\title{
O DISCURSO MÉDICO-HIGIENISTA NO BRASIL DO INÍCIO DO SÉCULO XX
}

\author{
THE DISCOURSE OF THE HYGIENIST PHYSICIAN IN THE EARLY 20TH CENTURY
}

Laerthe de Moraes Abreu Junior
Eliane Vianey de Carvalho

Resumo O objetivo deste trabalho é contribuir para a compreensão da relação entre higienismo e educação nas primeiras décadas do século XX no Brasil. Para isso, analisou-se o discurso médico-higienista presente nas teses da I Conferência Nacional de Educação, realizada pela Associação Brasileira de Educação em Curitiba, Paraná, em 1927, utilizando-se, principalmente, os livros Os anormais (2002) e A ordem do discurso (2009), ambos do filósofo francês Michel Foucault. O exame das teses, bem como a revisão de literatura em história da educação, possibilitou perceber que o objetivo dos médicos, intelectuais e políticos brasileiros da década de 1920 era formar uma consciência higiênica nacional voltada para o progresso do país, instaurando a preocupação com a saúde física, mental e social da população.

Palavras-chave I Conferência Nacional de Educação; discurso higienista; educação.
Abstract The purpose of this article is to contribute to the understanding of the relationship between hygienism and education in the early decades of the 20th century in Brazil. For this, an analysis was made of the discourse of the hygienist physician showcased in the theses of the 1st National Conference on Education, organized by the Brazilian Association of Education in Curitiba, Paraná, in 1927, mostly using the books titled "Os anormais" (The freaks) (2002) and "A ordem do discurso" (The order of discourse) (2009), both authored by French philosopher Michel Foucault. The examination of theses, as well as the review of the literature in the history of education, led to the realization that, in the 1920s, physicians, intellectuals, and politicians intended to form national awareness on hygiene focused on the progress of the country, establishing concern with the population's physical, mental, and social health.

Keywords 1st National Conference on Education; hygienist discourse; education. 


\section{Introdução}

A produção acadêmica no campo da historiografia sobre a presença de concepções higienistas na educação tem sido bastante significativa. Há mais de vinte anos - desde a tese de Marta Maria Chagas de Carvalho (1998) sobre higiene, moral e trabalho na educação na década de 1920, importantes pesquisadores da historiografia da educação brasileira atual, tais como Faria Filho (2000), Gondra (2004a), Vago (2002) e Vidal (2001), têm se dedicado a compreender as manifestações educativas no século XIX e na primeira metade do século XX no Brasil, momento em que o discurso higienista circulou intensamente no país.

A profusão de pesquisas sobre o higienismo não ocasionou esgotamento ou superexposição do tema; pelo contrário, desencadeou o interesse para a compreensão de como se formaram e se consolidaram projetos e propostas para a educação brasileira com fundamentos higienista e moral.

A manifestação do higienismo como um ramo da medicina se nota com muita visibilidade na sociedade europeia a partir de meados do século XIX, chegando logo depois ao Brasil. Nos cursos de medicina em nosso país, desde 1840 são defendidas teses pelos médicos, em seus trabalhos de conclusão do curso, que propõem desde a seleção de locais e modos para construir escolas, passando por medidas para a disposição das salas de aula, até os exercícios físicos para robustecer o corpo e restabelecer a saúde do aluno (Gondra, 2004a). A partir do início do século XX, são propostas medidas mais efetivas para a educação, tais como exames e testes das condições sanitárias tanto biológicas quanto psíquicas dos alunos. Nesse percurso pela educação, os médicos principalmente, mas não com exclusividade - pois também houve a participação de advogados, engenheiros e professores produziram discursos que defendiam uma pedagogia salvacionista para os males que afligiam o povo brasileiro.

A fonte principal para este trabalho foi o livro sobre a I Conferência Nacional de Educação (1927). ${ }^{3}$ Esse foi o primeiro encontro em nível nacional na década de 1920 realizado pela Associação Brasileira de Educação $(\mathrm{ABE})$ na cidade de Curitiba, Paraná. Estiveram presentes no evento autoridades civis, militares, políticas e eclesiásticas e "mais de quatrocentos congressistas, de trezentos alunos da Escola Normal Secundária de Curitiba e cerca de duas mil pessoas" (Costa, Shena, Schmidt, 1997, p. 15).

A I Conferência Nacional de Educação se insere nas ações da Associação Brasileira de Educação, proponente da conferência de 1927 e de outras duas na mesma década: em 1928 em Belo Horizonte, Minas Gerais e em 1929 em São Paulo, na capital. Na primeira metade do século XX, a ABE, fundada em 1924, teve participação ativa nos movimentos em prol da educação no país, principalmente os ocorridos na década de 1920. Composta por intelectuais, 
médicos, cientistas, educadores, juristas e religiosos, a ABE pretendia fazer da educação institucionalizada a principal transmissora dos valores prevalecentes da época, quais sejam a higiene, a moral e o patriotismo. Os integrantes dessa associação também estabeleciam em seus textos e palestras propostas concretas para a mudança da sociedade, tais como regras de higiene e de conduta moral, além de atitudes ligadas ao patriotismo como base para a formação da nacionalidade brasileira. No entanto, apesar dessa aparente convergência de princípios, não havia homogeneidade de interesses na $\mathrm{ABE}$, posto que surgiam acirradas disputas internas entre os participantes da associação, que formavam facções, diferenciadas por seus interesses: seja pela criação de um partido político, seja pela difusão do ideário moral católico, entre outras divisões internas (Carvalho, 1998, p. 53-60).

Intelectuais bastante conhecidos foram associados ou compuseram a diretoria da ABE: Anísio Teixeira, Lourenço Filho, Fernando de Azevedo, Manoel Bonfim, Belisário Penna, Afrânio Peixoto, entre outros. Segundo Carvalho, na ABE, "um grupo de intelectuais se autorrepresentou como 'elite' que se autoincumbiu de organizar o país" (1998, p. 39). Essa autora critica a simplificação com que muitos estudiosos trataram o projeto de uma política nacional que teve na $\mathrm{ABE}$ sua principal instância de disseminação, projeto esse considerado como portador da novidade e da ruptura com os velhos moldes da educação. É nesse contexto de propostas de condução de um povo considerado por suas elites como dependente e necessitado de uma intervenção firme em seu modo de viver que podem ser lidas as teses divulgadas durante a I Conferência Nacional de Educação.

$\mathrm{O}$ evento foi o primeiro acontecimento institucional na área da educação de alcance nacional, teve como tema central discutir "o grande problema da educação nacional" e foi considerado por Carvalho uma "festa cívico-nacionalista cuja finalidade última e razão de ser eram (nas palavras do comunicado oficial do evento) 'a unidade e grandeza da Pátria por um ensino bem orientado'” (1998, p. 308). A temática central da I Conferência Nacional de Educação foi dividida em quatro grupos:

$1^{\circ}$ ) A Unidade Nacional: a) pela cultura literária; b) pela cultura cívica; c) pela cultura moral.

$2^{\circ}$ ) A uniformização do ensino primário, nas suas ideias capitais, mantida a liberdade dos programas.

$3^{\circ}$ ) A criação de escolas normais superiores, em diferentes pontos do país, para preparo pedagógico de nosso professorado do ensino secundário e normal.

$4^{\circ}$ ) A organização dos quadros nacionais, corporações de aperfeiçoamento técnico, científico e literário (Carvalho, 1998, p. 310).

As relações entre a ABE e as Conferências Nacionais de Educação formam um campo de investigação que vem sendo explorado em diferentes 
vertentes. Muitos intelectuais envolvidos nas atividades desenvolvidas pela $\mathrm{ABE}$ nos anos 1920 viriam a ter um papel fundamental nos projetos educacionais da década seguinte. O mais notório é o Manifesto dos Pioneiros de 1932, liderado por Fernando de Azevedo. Se este é um dos personagens principais, e também dos mais explorados pela pesquisa historiográfica da educação, há outros intelectuais que merecem a atenção. É o que se pretendeu realizar nesta pesquisa: mostrar a relevância da I Conferência Nacional da Educação e destacar nas teses selecionadas os discursos higienistas que exemplifiquem um pouco daquele momento para a compreensão dos processos educativos de nossa história.

\section{Objetivos}

Esta pesquisa pretendeu realizar a análise do discurso higienista presente nas teses da I Conferência Nacional de Educação de 1927 e, desta forma, assinalar como as discussões sobre o higienismo e a educação se evidenciaram naquela época.

Propôs-se também a detectar, mesmo que de forma parcial, conceitos presentes nas teses sobre o higienismo e indicações para a constituição de práticas escolares, tais como a organização das salas de aula, com a separação dos sujeitos por suas presumíveis condições de acompanhar o ensino ministrado. Nesse entendimento, os alunos eram classificados por um suposto nível de inteligência. Pretendeu-se, ainda, analisar o discurso que embasava essa ação pedagógica que colaborou para segregar e afastar da escola aqueles sujeitos - principalmente crianças pobres - que não se adaptavam às regras de funcionamento da cultura escolar.

\section{Metodologia}

Para o desenvolvimento deste trabalho, leram-se textos sobre as relações entre educação e higienismo, e sobre fundamentação teórica para a análise das teses, tais como os livros Os anormais (2002) e A ordem do discurso (2009), ambos de autoria do filósofo francês Michel Foucault. Em seguida, foram lidas de forma abrangente as 98 teses publicadas na íntegra, com o objetivo de localizar aquelas relacionadas diretamente com o tema da pesquisa, isto é, a presença de conceitos higienistas, seja nos títulos, seja no corpo do texto. Por fim, foram selecionadas nove teses, lidas minuciosamente, a fim de detectar a presença do discurso higienista.

De forma a compreender a importância das contribuições de Michel Foucault para a metodologia utilizada neste trabalho, é preciso destacar seu 
livro Os anormais (2002), uma das obras mais significativas para a compreensão das relações do higienismo (e da moral) na sociedade. Foucault analisa a genealogia do discurso médico - aliás, do discurso médico-jurídico -, na França de meados do século XIX, em sua pretensão de normalizar a sociedade. Foucault não intenta realizar uma análise institucionalista ou ideológica; procura identificar as tecnologias de poder que utilizam esse discurso e tentam fazê-lo funcionar. Nesse sentido, a análise foucaultiana é fundamental para o trabalho, pois não há uma verdade a ser dissecada no discurso, e sim efeitos da verdade que se produzem no discurso.

Na leitura de Os anormais (2002), é possível estabelecer uma hipótese inicial para a presença do higienismo na educação. A genealogia do interesse por esse modo de encarar o higienismo pode estar na preocupação legal com o equilíbrio da sociedade e com os investimentos para que isso seja alcançado. Ou seja, é uma preocupação com a economia legal ${ }^{4}$ para o 'bom' funcionamento da sociedade. Nessa busca pelo equilíbrio, defendia-se que a sociedade se organizasse em harmonia e num clima de respeito à ordem. Que harmonia e ordem eram essas? Aquelas que atendiam o interesse dos que constituíam o poder vigente, do qual faziam parte médicos e juristas. Nesse contexto histórico, havia a necessidade da união dos esforços do saber médico - que instituía os conceitos que deveriam pautar o comportamento dos indivíduos - com os do aparato jurídico, o apoio legal para realizar a vigência dos parâmetros almejados pelo saber médico. Com isso, eram estabelecidas tecnologias de poder.

Foucault explicita o que são tecnologias 'positivas' de poder: as ações efetivas pautadas pelas instâncias político-administrativas visando à produção de comportamentos, tanto individuais quanto sociais (Foucault, 2002, p. 59). Para isso, as tecnologias de poder se valem da produção e difusão de normas e procedimentos visíveis e palpáveis em sua natureza operativa, em que o controle ideológico não é o mais importante, pois a repressão "só figura a título de efeito colateral e secundário" (Foucault, 2002, p. 64).

O que Foucault apresenta é um novo modelo de tratamento que não se faz simplesmente pela exclusão; 5 que se volta agora para o que foi proposto e adotado na Idade Média para os pestilentos. É um modelo de inclusão cujo método se define pela "observação próxima e meticulosa (...) e implica uma espécie de aproximação cada vez mais sutil do poder aos indivíduos" (Foucault, 2002, p. 58). Nessa concepção foucaultiana, o poder não requer uma análise ideológica, posto que está "integrado no jogo, na distribuição, na dinâmica, nas estratégias, na eficácia das forças" (Foucault, 2002, p. 65); ou seja, o poder não está mais afastado do cotidiano, mas integrado vivamente às práticas sociais.

$\mathrm{Na}$ investigação dos discursos produzidos nas primeiras décadas do século XX sobre higiene e educação, visando à melhoria das condições 
do povo brasileiro, podem ser utilizados os conceitos foucaultianos, justamente pelo entendimento de que esses discursos têm caráter de inclusão, qual seja o de fornecerem um modelo de educação que responde ao tratamento das carências do povo brasileiro, mas que deixa manifesto quem dita o poder e quais são as normas e procedimentos a serem seguidos.

\section{O contexto político-cultural da década de 1920 e o higienismo}

A década de 1920 no Brasil foi um período de instabilidade institucional. Foram três presidentes: Epitácio Pessoa (1919-1922), Artur Bernardes (19221926) e Washington Luís (1926-1930), que procuraram acomodar a governabilidade diante das turbulências políticas (Lustosa, 1989). Aconteceram muitos eventos políticos e culturais significativos. Entre eles, em 1922, a comemoração do centenário da Independência, com a realização da Exposição Internacional no Rio de Janeiro, a Semana de Arte Moderna em São Paulo, o levante do Forte de Copacabana e a criação do Centro Dom Vital, de tendência católica conservadora (Horta, 1994); em 1923, Roquette Pinto fundou a Rádio Sociedade do Rio de Janeiro (hoje, Rádio MEC); em 1924, foi criada a Associação Brasileira de Educação, entidade que procurou desenvolver um papel social bem mais amplo do que o de atuar apenas na educação (Carvalho, 1998); em 1925, a Coluna Prestes, com mil e seiscentos homens, percorreu dezenas de milhares de quilômetros pelo Brasil por três anos (Ribeiro, 1986), e foi decretada a Reforma Rocha Vaz por parte do governo federal, mas seu alcance limitado ao ensino secundário teve efeito inócuo na educação do país (Mourão, 1962; Horta, 1994). No entanto, educadores de diferentes estirpes promoveram reformas estaduais nessa década: Sampaio Dória, em São Paulo (1920), Lourenço Filho, no Ceará (1923), Anísio Teixeira, na Bahia (1925), Carneiro Leão, em Pernambuco (1926), Francisco Campos e Mario Casassanta, em Minas Gerais (1927) e Fernando Azevedo, no Distrito Federal (1928) (Werebe, 1997).

É importante assinalar a presença do discurso médico-pedagógico nos planos para a educação nacional na primeira metade do século XX. Esses discursos já vinham sendo produzidos desde o século XIX nas teses defendidas na Faculdade de Medicina do Rio de Janeiro (Gondra, 2004a). Os conceitos envolvidos nas tramas do discurso médico-pedagógico passavam pelo crivo da ciência. O objetivo maior era formar o cultivo de maneiras civilizadas, inculcadas por um cuidadoso processo que abrangesse não só a escolarização, mas também a orientação de outras práticas e costumes da vida social. Isso significava incluir no espectro das medidas fundamentadas pelo discurso médico-pedagógico diversas práticas, como cuidados com a higiene corporal, vestimentas mais adequadas ao clima e até indicações para 
as construções arquitetônicas, como o tamanho apropriado das salas e a posição das janelas (Gondra, 2004).

A responsabilidade pela implantação dessas medidas voltadas para a saúde e a higiene estava em grande parte depositada na classe médica. A medicina era considerada portadora do saber científico (Gondra, 2004a) e percebida como capaz de corrigir e implantar hábitos e influenciar práticas sociais - dentre elas a escolarização -, pela força persuasiva da argumentação científica presente no discurso médico.

O trabalho de Carvalho (1998) foi pioneiro em analisar a presença do higienismo na formação de um projeto educacional brasileiro no início do século XX. Ao pesquisar os arquivos da ABE do período 1924 a 1931, Carvalho acentua nos discursos cívicos e profiláticos da associação a questão sanitária como marca da situação nacional, entendendo-se neles a ação educacional como uma obra de saneamento dos males que afligiam o povo brasileiro, visto como indolente e doente, e necessitado de uma atuação higiênica por parte da elite para debelar esses males (Carvalho, 1998, p. 145).

Desde esse trabalho, 6 o tema higienismo passou a estar presente na produção de vários autores com pesquisas diversificadas e relevantes no campo da historiografia da educação, como é o caso da tese de doutorado de Meily Linhales (2006), em que ela analisa, de 1925 a 1935, as relações estabelecidas entre o esporte e a educação escolar nos projetos culturais em circulação na Associação Brasileira de Educação. Ao situar a criação da Seção de Educação Física e Higiene, Linhales afirma:

(...) a Seção experimentou, ao longo de sua existência, diferentes níveis de envolvimentos com as duas temáticas (a educação física e a higiene). No seu nascedouro, a higiene teve papel preponderante. Campanhas instrutivas para higienizar o povo e cursos de aperfeiçoamento em higiene, destinados às professoras primárias, constituíram prioridades entre 1925 e 1928. Essas ações eram sempre coordenadas por médicos atuantes tanto na $\mathrm{ABE}$ como em outras entidades e redes de sociabilidade que priorizavam a educação higiênica e sanitária. Educação e higiene foram pensadas e produzidas, na $\mathrm{ABE}$, de forma bastante correlacionadas, como duas dimensões complementares no projeto 'sanitário' da regeneração social (Linhales, 2006, p. 152).

Na análise de Linhales (2006), percebe-se a importância dada à higiene no 'projeto sanitário' da ABE, liderado, principalmente, por médicos filiados à entidade.

Em outro texto de Carvalho (2006), a autora destaca a campanha educacional pela saúde, moral e trabalho, que compunham o trinômio sobre o qual se deveria assentar a 'educação do povo'. Essa campanha defendia os seguintes pontos de vista: hábitos saudáveis moralizam; uma vida virtuosa 
é saudável; moralidade e saúde são condições e decorrência de hábitos de trabalho; e uma vida laboriosa é uma vida essencialmente moral e saudável. Dessa forma, caberia ao professor 'guiar a liberdade' do aluno, de modo a garantir o 'máximo de frutos', obtido com um mínimo de tempo e esforços. Regrar a liberdade e coibir a paixão eram práticas sutis para ajustar "os homens a novas condições e valores de vida-eficácia e disciplina" (Carvalho, 2006, p. 306-307).

Na mesma direção, Gondra (2004b) assinala a manifestação médico-higienista na educação. A escola deveria ocupar-se da formação física, moral e intelectual das crianças e jovens, por meio de numerosas práticas, indicadoras da extensão da intervenção imaginada pelos homens da ciência médica (Gondra, 2004a, p. 122).

Em outro trabalho, Gondra (2000), ao discorrer sobre as relações entre medicina, educação e sociedade, reflete, também, sobre o processo de constituição da ordem médica no Brasil, evidenciando as características da razão médica, sua institucionalização, seus agentes e sua produção discursiva voltada para o objeto educacional (Gondra, 2000, p. 519).

Já Vago (2002) problematiza o movimento de afirmação de uma nova cultura escolar em Belo Horizonte nas duas primeiras décadas do século XX, na qual se depositou a esperança de realizar uma 'revolução dos costumes' nas crianças, especialmente da população pobre, e, ao mesmo tempo, procurou-se corrigir seus hábitos e implantar-lhes maneiras consideradas civilizadas. O autor trata ainda do investimento feito na época sobre o corpo das crianças, no âmbito da escola.

\section{Análise das teses}

A divulgação das teses da I Conferência Nacional de Educação, por meio da publicação do Instituto Nacional de Estudos e Pesquisas Educacionais Anísio Teixeira (Inep) em 1997, permitiu que elas fossem exploradas em análises de diversas temáticas: infância, ensino primário, ensino secundário, formação de professores, entre outras. No entanto, material tão vasto ainda possibilita outras análises, principalmente no que diz respeito a perscrutar a intencionalidade dos discursos nele contidos. Dessa forma, se o interesse deste trabalho se volta para o discurso higienista, é necessário avaliar também teses que abordam temas correlatos ou que aparentemente não tratam do assunto, por não trazerem os termos higiene e higienismo em seus títulos. Na realidade, a palavra higiene só aparece no título de três teses, ${ }^{7}$ mas o conceito está presente em outras.

A higiene se relaciona com outros enunciados, como doença física e doença mental, associados à ordem social, à educação moral, ao patriotismo 
e à degeneração da raça. Na tese número 78, "Pela perfeição da raça brasileira", do professor Nicolau Meira de Angelis da Escola Normal Primária de Ponta Grossa, Paraná, lê-se que o conceito de raça deveria ser encarado "sob prismas diversos e obedecer às leis imutáveis da evolução humana" (De Angelis, 1997, p. 439). Assim, era proposta uma visão de caráter biológico que, no entanto, não impediria ser modificada a partir de um trabalho educativo, recebendo "as salutares influências da higiene, do trabalho intelectual, moral, artístico e físico" (De Angelis, 1997, p. 439). O que o autor quer dizer é que, se havia leis biológicas imutáveis, ou seja, se havia diferenças de raças, essa condição natural não era determinante, pois seria possível utilizar as 'salutares influências' desse conhecimento científico, introduzindo o higienismo na educação, para minorar essa desigualdade de origem. Essa ação é tipicamente inclusiva no sentido foucaultiano, pois propunha que o ambiente escolar fosse favorável para o trabalho pedagógico em prol da melhoria da 'raça brasileira':

Nosso dever como professores é difundir nas escolas, às classes mais adiantadas, as consequências da sífilis, do alcoolismo e outros fatores de degenerescência; é tratar da educação sexual, mostrar aos jovens as consequências de uma vida desregrada, os benefícios da virtude, de uma vida moralizada, de uma vida cristã (De Angelis, 1997, p. 443).

Já na tese número 73, "Formação do caráter do povo brasileiro", a professora Lucia V. Dechandt, também da Escola Normal Primária de Ponta Grossa, Paraná, relacionava a grandeza do povo brasileiro no que diz respeito ao aperfeiçoamento moral e à formação de seu caráter:

Mestres e pais influem sobre o caráter, e nisto convém que pais e professores cuidem da saúde, da higiene dos educandos, já lhes aconselhando a prática do bem, já os repreendendo quando não praticarem os princípios elementares da higiene e do asseio (Dechandt, 1997, p. 428).

Aqui se nota a relação direta entre prática do bem (educação moral) e higiene e asseio, em uma associação de valores entre as duas ações, de naturezas diversas, que se integram na mesma prática. Com isso esperava-se que, por meio da educação moral e da introdução de hábitos de asseio e cuidados com a saúde, as crianças internalizassem esses princípios. A autora prossegue:

Um outro aspecto na educação do caráter é o do regime: a atividade é condição de saúde e harmonia; preguiça, ao contrário, é fonte de males e de vícios. É necessário combater a preguiça; para isso deve se aproveitar como arma o trabalho (Dechandt, 1997, p. 426). 
Novamente a autora estabelece uma ligação entre 'educação moral' e 'educação do corpo', e descreve como dispositivo de combate à 'preguiça' o 'trabalho' e atividades que proporcionem 'saúde e harmonia', evitando males e vícios. Quando se afirma que a preguiça causa males e vícios, acaba-se por produzir um efeito de verdade, pois não há relação direta entre causa e efeito. Nota-se apenas um conjunto de enunciados persuasivos, presentes em outras partes da tese, como no trecho a seguir: "Vejamos os males que advêm do álcool e do jogo, grandes inimigos do progresso de um povo, auxiliares da degeneração do caráter e da degradação moral e a causa de muitos males físicos" (Dechandt, 1997, p. 428).

Outro tema muito presente nessa visão higienista era o papel das mulheres. A tese de número 43, "Sobre a unidade nacional: pela cultura cívica e pela cultura moral", de Fernando Luís Osório, do Instituto Histórico e Geográfico do Rio Grande do Sul, afirmava:

E à mulher, que pela sua natureza moral, pureza e ternura é superior ao homem, cabe elevar o nível moral da sociedade, a proteção da raça, da mocidade, o combate à miséria e aos flagelos dos povos, preciosamente cooperando no ensino e na higiene (1997, p. 260-261).

Osório delega à mulher a responsabilidade de elevar o nível moral da sociedade por meio da educação moral e higiênica. Além disso, essa é uma tese prescritiva, pois sugere a criação de vários órgãos nacionais - inclusive o Ministério da Educação Nacional - como medidas para se forjar um

(...) sistema cultural 'sistematizante' contra o 'perigo brasileiro', escudando o Brasil social, a unidade da Pátria, a República baseada na difusão das luzes e da moral, de males que seus filhos possam porvir: míngua de instrução, depauperamento do caráter, definhamento do patriotismo consciente, organização das elites, classes dirigentes dos chefes, das populações, das forças ativas da Nação (...) (Osório, 1997, p. 261).

Eram diversas as procedências discursivas, mas, ao serem reunidas num fórum nacional, pretendiam se valer de seu efeito de verdade, buscando uma postura hegemônica que se acomodava numa difusa visão de mundo: a sociedade brasileira estava tomada por 'males e vícios' que eram 'inimigos do progresso' e degeneravam o caráter e a moral do povo. Além de provocarem 'muitos males físicos' (da verminose ao alcoolismo), esses males e vícios eram um perigo porque impatrióticos.

Esse enfoque moral do discurso higienista não só determinava os hábitos de conduta, como também as formas de lazer consideradas saudáveis, procurando controlar e indicar a literatura, os filmes, os programas radiofônicos, as peças teatrais etc. 8 
Alguns intelectuais da época acreditavam que deveria haver uma educação moral dirigida às 'elites' e outra para as 'massas', como apontava Alba Cañizares Nascimento, em tese apresentada na II Conferência Nacional de Educação, realizada em 1928 na cidade de Belo Horizonte. Era preciso que os professores tivessem "formação moral teórica (...) instrução pura e princípios científicos", pois "o ato [educativo] só era completamente moral para as elites, esses tipos superiores da humanidade, que dirigem, pela força da seleção, massas humanas, corporações, províncias e nações" (Cañizares apud Carvalho, 1998, p. 331), enquanto para as 'massas',

Cañizares programava outro tipo de moralidade. Impunha-se, desde o início da vida escolar, conduzir os educandos à admiração pelas doutrinas que levem à concepção e ao sentimento do dever, da responsabilidade, do mérito, do demérito, do direito em geral (Carvalho, 1998, p. 333).

O 'adestramento de cavalos' - a educação moral das massas -, 'base do ensino nacional', era obra 'eminentemente conformadora', obra de moldagem. Era "conformar no indivíduo sua moral (...) com as altas necessidades da vida coletiva" (Carvalho, 1998, p. 332), obrigando-o à "adaptação, pela disciplina" (Carvalho, 1998, p. 333).

A necessidade de 'formação teórica' para o professor, educação essa que somente seria possível para as 'elites', residia no fato de o professor ser o dispositivo usado para educar as 'massas' e as 'elites' de maneira diferenciada. Dessa forma, era preciso dirigir corretamente o ensino moral adequado para cada grupo, seja para 'os tipos superiores da humanidade', seja para 'adestrar cavalos'.

Dos autores que abordaram a importância do higienismo na educação, o médico Belisário Penna, na tese número 1, "Por que se impõe a primazia da educação higiênica escolar", é o mais incisivo:

É fato fora de discussão, constituindo verdade axiomática, que a saúde, isto é, a normalidade fisiológica da vida, é condição imprescindível de eficiência, de aperfeiçoamento incessante e de rendimento útil de qualquer ser organizado - vegetal, animal ou homem (Penna, 1997, p. 29).

Embora a citação não traga a palavra higiene em seu texto, ela utiliza outro termo similar: a 'saúde', considerada 'condição imprescindível de eficiência'. Além disso, o argumento inicial da tese - 'fato fora de discussão', 'verdade axiomática' -, demonstra que a autoridade que iria manifestar-se sobre a 'primazia da educação higiênica escolar' tentava utilizar um argumento supostamente inquestionável em seu discurso. O efeito de verdade se manifesta quando se lê que o discurso médico não tem dúvidas sobre seu 
papel regenerador da sociedade e pode se valer dessa ordem autodelegada para conduzir os processos educacionais. Nesse sentido, o papel do discurso médico era o de:

Ressaltar a importância capital da educação higiênica e eugênica popular, começada desde a escola primária, a fim de, por esse ensino fundamental, formarmos a 'consciência sanitária nacional', isto é, um estado de espírito coletivo consciente, convencido e firme, sobre a importância dos problemas higiênicos e eugênicos na vida do indivíduo e da sociedade (Penna, 1997, p. 29).

Esse é um discurso que utiliza a sua força persuasiva para conclamar as pessoas a formarem "a consciência sanitária nacional", pela "defesa e melhoramento incessante da vida, da sociedade e da espécie" (Penna, 1997, p. 29), utilizando, ainda, uma postura prescritiva, bem de acordo com a sua formação médica:

A missão da educação moderna é mais biopsicossocial do que literária, consistindo no respeito às leis inflexíveis da biologia humana, pela prática dos preceitos da higiene e da eugenia, para que saibam e possam todos cumprir a finalidade biológica do homem, de que resultam: os deveres individuais (...), os deveres interindividuais (...), os deveres do indivíduo em relação à espécie (...).

A inobservância desses deveres acarreta (...): a indolência, a doença, o descaso pela higiene física, mental e moral, as intoxicações euforísticas voluntárias, o suicídio, os atentados contra os bens e os direitos do próximo, o homicídio, o egoísmo, a falsa concepção do casamento, a degeneração da raça, o luxo, a concupiscência, a prostituição, o jogo, a imoralidade, o latrocínio, a mortalidade infantil, a irreligiosidade, o antipatriotismo, a corrupção, o suborno, a tirania, o pavor à liberdade e à verdade e o predomínio da força sobre a justiça e o direito (Penna, 1997, p. 32).

Como se pode notar, para Belisário Penna, todos os problemas se resolveriam com uma correta educação, higiênica e eugênica. Por isso, enfatizava a necessidade urgente de tais medidas, apontando ainda as consequências prejudiciais às pessoas caso não cumprissem seus 'deveres' para consigo e para com a sociedade. A educação, nos dizeres do médico, deveria enfatizar mais os hábitos de saúde e higiene do que propriamente a instrução.

O médico eugenista Renato Kehl, na apresentação da tese número 75, “O problema da educação sexual: importância eugênica, falsa compreensão e preconceitos - como, quando e por quem ela deve ser ministrada", afirmava:

No Congresso Internacional de Higiene havido em maio de 1923 em Paris, bem como em muitos outros certames, não só de médicos, higienistas, como de pedagogos e eugenistas, o ensino sexual foi muito debatido, vencendo a corrente que entende 
ser ele imprescindível para a defesa do indivíduo, da sociedade e do progresso biológico da espécie (Kehl, 1997, p. 435).

Na tese, Renato Kehl trata a educação sexual como mais um tema higienista. Ao utilizar os conceitos de Freud, Kehl faz valer outra forma de efeito de verdade, pois o que está em jogo não é a defesa do respeito à manifestação da sexualidade na infância, 9 e sim a 'defesa da sociedade', com o objetivo de evitar epidemias, como vários tipos de doenças venéreas. 10 E ainda, ao preocupar-se com o 'progresso biológico da espécie', revela a visão eugênica do médico, pois esse progresso só seria possível, em seu entender, com os seguintes 'cuidados higiênicos a praticar', apresentados ao longo da tese: exames pré-nupciais, resguardar-se (tanto o homem quanto a mulher) para o matrimônio, com o que se evitaria a degeneração de seus descendentes, ou seja, a procriação de indivíduos considerados propensos a apresentarem 'defeitos' físicos, mentais ou morais - os anormais.

A autora da tese número 13, "Seleção e estalonagem das classes infantis pela psicometria e pela fisiometria", é Lúcia Magalhães, secretária-geral da Associação Brasileira de Educação em 1929, tendo publicado, em 1936, juntamente com Joaquim Ribeiro, o livro Estrutura e aprendizagem: novos rumos da psicologia.

Na tese, a autora abordava os sistemas e métodos de avaliação usados por Binet, Simon, De Sanctis, Terman, Descoeudres, Bovet. Esses autores estudaram crianças diversas por meio de indicadores como raça, costumes e meio de vida. Lúcia Magalhães afirma que no Brasil, até aquele momento (1927), somente Medeiros e Albuquerque havia tratado do assunto, porém fizera uma tradução fiel dos testes de Binet,11 o que ela julga "inadequado para nossa gente e nossa raça" (1997, p. 107).

Seguindo o exemplo de Terman, que adaptou os testes 'universalmente' conhecidos para as 'necessidades da raça norte-americana', Lúcia Magalhães também fez "modificações para melhor atender a raça brasileira" (1997, p. 107). O objetivo da aplicação dos testes era verificar o desenvolvimento mental da criança. Eles poderiam ser aplicados por ocasião da admissão aos cursos primários, secundários e superiores. Lúcia Magalhães afirma que, com isso:

Será possível fazer uma seleção racional entre crianças normais, anormais e retardadas, evitando assim os males incalculáveis que resultam fatalmente da fusão de capacidades diversas numa escola ou numa coletividade (...) a seleção de alunos criará, evidentemente para o aluno normal ou supranormal, possibilidade de adiantamento muito mais rápido e mais eficiente, pois não haverá na turma o elemento 'criança anormal' atrasando o curso regular das aulas. Esses alunos retardados não se sentirão mais desanimados pelos sucessos constantes de seus camaradas 
mais favorecidos, sucessos tão facilmente obtidos, que convencem cada vez mais a criança anormal da inutilidade do seu esforço (Magalhães, 1997, p. 108).

O que chama atenção logo de início é a naturalidade com que a autora utiliza os termos anormal e retardado, como se constituíssem uma categoria inquestionável. Assim, fica patente a defesa da criação de classes diferentes para os alunos, de acordo com a classificação da intelectualidade em 'normal', 'anormal' ou 'retardada', com a alegação de que permitiria melhor desempenho para todas as categorias. A tese leva a crer que, ao serem implantados nas escolas, os testes acabariam por beneficiar os ditos 'normais', uma vez que seriam eles os indivíduos desejados para promoverem o progresso da nação. Não coincidentemente, os 'normais' seriam os indivíduos pertencentes à classe média ou à classe alta da população, na maioria das vezes a parcela com acesso aos 'códigos sociais' usados para elaborar os testes de avaliação. Um exemplo do que aqui está sendo apontado é o teste citado pela autora para crianças de oito anos. O item 5 pede: "Compreensão e vocabulário - definição de vinte palavras do vocabulário organizado (vide anexo 1)". No referido anexo 1, que explica a tarefa, a autora afirma: “Daremos a seguir um vocabulário de sessenta palavras usuais, estabelecido depois de grande número de observações e de acordo com as condições de vida e de ambiente da criança brasileira de classe média" (Magalhães, 1997, p. 112).

O parâmetro avaliativo é claro: 'criança brasileira de classe média'. Aí está um exemplo da fraqueza epistemológica dos testes. Como é possível classificar os indivíduos justamente usando um padrão que beneficia apenas uma parcela da sociedade?

Em outro teste, também para crianças de oito anos, é solicitado ao aluno que conte seis moedas diferentes. Como é possível afirmar que uma criança de oito anos que não consegue contar seis moedas diferentes é 'anormal'? E se, porventura, essa criança não tem contato com moedas? O resultado dos testes vai depender do tipo de experiências sociais vivenciadas pela criança. Em sua concepção, a educação deve satisfazer duas condições:

A primeira, de ordem pedagógica, exige que todo indivíduo, qualquer que seja seu desenvolvimento físico ou mental, aprenda a trabalhar dando o máximo de rendimento que lhe for possível. A segunda, condição higiênica, permite que a criança evite todo esforço demasiado no cumprimento da primeira cláusula. Daí a vantagem das classes selecionadas (Magalhães, 1997, p. 114).

Uma das principais manifestações do discurso higienista era a preocupação com um conceito não muito claro de progresso da nação. Nesse sentido, não haveria progresso sem indivíduos saudáveis e produtivos. Partindo dessa premissa, fazia-se necessária a eficácia dos métodos educativos. A separação 
em classes para 'normais' e 'anormais' era justificada pelas diferentes capacidades de aprendizado das crianças. Nessa concepção, é coerente dizer que a criança classificada como 'anormal' 'evite todo o esforço demasiado', com o que confirma a ideia de que a diferença de determinada criança em relação às demais é imutável: seria inútil o esforço de aprendizagem da criança fora do ambiente previamente estabelecido pelos educadores, fundamentados em ideias científicas.

São duas as áreas de interesse de Lúcia Magalhães. Até agora se abordou a psicometria. Sobre a outra área, a fisiometria, dizia a autora:

É necessário que as crianças sejam escalonadas não apenas pelo seu Q.I. [quociente de inteligência], mas também pelo seu desenvolvimento físico. E que um bom índice físico permite um prognóstico de um Q.I. elevado. (...) assinalamos ainda a importância da notificação do ambiente em que viva a criança, sobretudo a de classe pobre - vilas operárias, casas isoladas ou habitações coletivas. Foi-nos fácil observar que as crianças nascidas e criadas em habitações coletivas tinham sempre um índice fisiométrico inferior (Magalhães, 1997, p. 115).

A citação revela o determinismo da autora ao afirmar que as crianças de 'classe pobre, nascidas e criadas em habitações coletivas' apresentavam um 'índice fisiométrico inferior'. O que poderia ser abordado levando-se em conta a precariedade da situação social e econômica decorrente das ações de políticas públicas era tratado como estigma de um determinado grupo de crianças. Mais uma vez se manifesta a inconsistência epistemológica: como se define 'classe pobre'? Quais as características de ter nascido e crescido em habitações coletivas? Como isso interfere, comprovadamente, na aprendizagem?

Nas teses é recorrente o uso da educação como instrumento para disseminar não só os conceitos higienistas, como também, eugenistas. A tese 82 "Educação e higiene mental", de Álvaro Guimarães Filho, professor de medicina e membro da Liga Paulista de Higiene Mental, é um bom exemplo. Nela, ele defende a importância de o professor conhecer os preceitos da higiene mental, uma vez que estará em contato direto com as crianças. Essa proximidade torna o professor - juntamente com o psicólogo e com o psiquiatra, e com a ajuda dos testes de Alfred Binet - responsável por identificar e selecionar crianças para colocá-las em classes separadas, segundo supostos níveis diferentes de anomalias mentais. Em seu discurso, ele defendia a criação de 'escolas para os anormais', e colocava o 'professorado brasileiro' como principal responsável por esse trabalho.

Alguém que leia desatentamente a tese de Álvaro Guimarães Filho pode não notar que, embora o discurso seja amparado pelo dito 'saber científico', ela é fraca epistemologicamente ao tratar da higiene mental. Isso se confirma nos diagnósticos de 'anormalidade' presentes na tese. Na maioria das vezes, 
eles foram obtidos por meio da aplicação dos testes de quociente de inteligência de Alfred Binet, ou mesmo por outros métodos, pois, segundo o autor, os psiquiatras usam "processos mais práticos com os quais poderiam julgar da incapacidade do examinado" (Guimarães Filho, 1997, p. 466), "mandando o doente ou transmitir um recado ou reconhecer moedas e cores, classificando os grandes anômalos mentais [fora dos padrões de normalidade] em casos de êxito, em imbecilidade e, em casos de incapacidade para esses misteres, em idiotia" (Guimarães Filho, 1997, p. 467). É possível identificar no quadro a seguir a utilização de termos triviais como 'conceitos científicos'.

\section{Quadro 1}

Termos usados para caracterização da higiene mental

\begin{tabular}{|c|c|}
\hline Moléstias do sistema nervoso & Doenças mentais e nervosas \\
\hline Higiene mental & $\begin{array}{l}\text { parte da higiene que estuda por todos os meios e modos as causas imediatas } \\
\text { ou longínquas que venham perturbar o psiquismo humano, investiga os meios } \\
\text { de profilaxia. }\end{array}$ \\
\hline Vontade & está relacionada ao instinto da criança \\
\hline Pernicioso & mal, prejudicial \\
\hline Anormais & $\begin{array}{l}\text { portadores de debilidade mental (causado na maioria das vezes pelo } \\
\text { alcoolismo e/ou sífilis dos antecedentes) }\end{array}$ \\
\hline Débil mental & $\begin{array}{l}\text { dividido em três grupos: debilidade mental propriamente dita, imbecilidade e } \\
\text { idiotia }\end{array}$ \\
\hline $\begin{array}{l}\text { Testes de inteligência de } \\
\text { Alfred Binet }\end{array}$ & servem para identificar (classificar) os diferentes níveis de 'debilidade mental' \\
\hline Anômalo mental & servem para identificar (classificar) os diferentes níveis de 'debilidade mental' \\
\hline Fraco de espírito & anormal \\
\hline Psicopata & anormal, incapaz de aprender por si só \\
\hline Retardado & anormal, pessoa com desvio mental pouco acentuado \\
\hline
\end{tabular}

Fonte: os autores.

A variedade de termos sinônimos e também a sua repetição funciona como modo de educar a população, à qual Álvaro Guimarães Filho se dirigia, utilizando argumentação pretensamente convincente. O que significa 
pernicioso, débil mental, imbecilidade, idiotia? O simples fato de ter sido escrito por uma autoridade médica lhe garante caráter científico? É importante ressaltar que muitos assuntos tratados nas teses eram também discutidos ou apresentados em outros eventos. 12

Parece ser o objetivo dos adeptos ou simpatizantes do higienismo e da eugenia educar o maior número de pessoas por meio da divulgação sobre a maneira de viver considerada por eles 'indispensável' para o 'melhoramento da raça' e o progresso do país. Dessa maneira, acreditavam que a educação era o principal meio, pois atingiria as crianças desde a mais tenra idade, elas transmitiriam os preceitos de higiene que haviam aprendido para os seus familiares e fariam uso deles por toda a vida. O objetivo dos higienistas era o de criar um 'molde nacional', nos dizeres de Carvalho, "transformando-as [as crianças] em seres raciocinantes e úteis no meio em que vivem" (1998, p. 467).

Partindo dessa concepção, era necessário formar, entre a população, indivíduos que atuassem como 'soldados' no combate à ignorância e à doença. E o professor seria, "antes de tudo, o braço direito do higienista e um dos grandes elementos de que dispõe a sociedade para salvaguardar os seus interesses, principalmente os de ordem intelectual e moral" (Carvalho, 1998, p. 468-469). Portanto, fica explícita a relação entre o discurso médico e a educação, quando se tenta colocar o professor como porta-voz da causa higienista e educar seus alunos com base nessa concepção.

A intervenção higienista ia muito além da preocupação com a saúde física e mental. Ela também lidava com as questões relativas ao espaço físico dos estabelecimentos, tais como: escolas, internatos, hospitais, presídios, etc. É possível observar essa atenção aos estabelecimentos na tese de número 84 "A higiene nos internatos: estudos das condições sanitárias dos internatos de São Paulo", do médico Eurico Branco Ribeiro. Na tese, ele descreve a inspeção feita em 1926 em dez colégios de internato 'escolhidos aleatoriamente' na cidade de São Paulo. Observa-se a análise minuciosa das condições sanitárias feita pelo médico no próprio resumo de itens, dividido em três partes:

I - O meio escolar: 1) Localização e disposição geral; 2) Edifício: a) generalidades, b) salas de aula, c) dormitórios, d) refeitórios, e) enfermarias, f) cozinha, g) instalações sanitárias, h) asseio e conservação; 3) Material escolar; 4) Recreios.

II - O aluno: 1) Assistência médica e dentária; 2) Profilaxia; 3) Contato entre internos e externos; 4) Enxoval.

III - Programa escolar: 1) Horários; 2) O ensino de higiene; 3) Educação sexual (Ribeiro, 1997, p. 490).

Em todos os itens e subitens anteriormente identificados, fica evidente o olhar médico-higienista. A tentativa de se instaurar um modelo higiênico e sanitário para a educação torna-se manifesta no modo como o autor 
descreve minuciosamente os estabelecimentos de ensino e indica como cada um desses itens deve 'funcionar':

Quanto aos objetos de uso diário nos refeitórios, certo que seria o ideal cada interno servir do que é unicamente seu. A prática impõe algumas restrições para a louça, por exemplo, que sempre deve ser lavada em água fervente; o talher, o copo, o guardanapo, é de conveniência que sejam individuais - e em muitos colégios o são. Noutros, o indiscutível valor profilático do copo individual não faz jus a uma disposição regulamentar que o reconheça. Um deles não obriga o interno a possuir seu copo; outro apenas tentou impor essa medida higiênica aos seus alunos (Ribeiro, 1997, p. 490-491).

A constante preocupação com a saúde do interno aparece na descrição de cada detalhe das condições sanitárias dos estabelecimentos, como o local da construção do edifício, o tipo de piso, o local das janelas, o horário das refeições, o tempo de repouso, as atividades físicas, o contato dos alunos internos com os alunos externos, o espaço para cada aluno na sala de aula, os tipos de móveis, tais como as carteiras para estudos mais apropriadas. A tese chega ao requinte de detalhar assuntos como limpar o edifício de modo a não levantar poeira e até mesmo o uso de palitos nos refeitórios.

Eurico Branco Ribeiro afirma que foi orientado nesse trabalho pelo médico Nuno Guerner - autor do n. 22 do boletim A educação hygiênica escolar, publicado em 1924 pelo Instituto de Hygiene de São Paulo. Essa seria uma das justificativas para a realização de um trabalho meticuloso, inspirado em higienistas como Friedrich Erismann, Adolf Baginski, Leo Burgenstein, Rudolf Stefan Weigl, Friedrich Oesterlen etc., em arquitetos e autoridades sanitárias de diversos países - Rússia, França, Suécia, entre outros - e nos códigos sanitários de alguns estados brasileiros.

A tese, uma das mais extensas do livro sobre a I Conferência Nacional de Educação, traz ainda uma comparação entre os internatos religiosos e os leigos em relação à limpeza, defendendo que "há mais asseio nos colégios religiosos, onde são as próprias irmãs ou irmãos que fazem a cozinha, ou é sob as vistas imediatas deles que o serviço se executa", (Ribeiro, 1997, p. 496) do que em outros, no caso os internatos leigos.

João Maurício Moniz de Aragão, médico e membro da Associação Brasileira de Educação, é o autor da tese de número 80, “Assistência médica à infância escolar: cadernetas sanitárias". Nela, o autor, por um lado, idealiza a vida no campo - 'fácil vida no campo', 'clima e vantagens inerentes ao campo'; por outro lado, critica a ignorância e os atrasos com que lá chegavam os processos de educação 'crivados de erros e defeitos'.

Ao tratar da cidade, apontava como problema tanto o 'acúmulo excessivo de habitantes' quanto os 'detritos e excretas' lançados pelas usinas 
industriais. O Brasil, na concepção médico-higienista, estava preso em uma dupla armadilha: a da pretensa vida saudável do campo, mas com os 'atrasos e defeitos' com que nela chegavam os ensinamentos modernos; e a da vida na cidade, enfrentando os desafios do crescimento industrial, onde, além dos problemas de saúde decorrentes dos detritos industriais, havia mães que, para ganharem seu sustento, 'deixam as crianças entregues a terceiros', que tomavam conta de "inúmeras crianças, de origem e procedência diversas, na mais completa promiscuidade e imundície, onde facilmente se propagam as doenças que destroçam as populações infantis" (Moniz de Aragão, 1997, p. 452).

Para Moniz de Aragão, a solução desses problemas sociais era fundar casas especiais nas cidades, “onde médicos, de preferência especialistas, acompanhariam a saúde de cada criança através de cadernetas sanitárias individuais (...), para não serem transmissores de moléstias" (Moniz de Aragão, 1997, p. 453). Além do acompanhamento individual, por meio da caderneta sanitária, Moniz de Aragão propunha ainda exercícios físicos, ou melhor, um 'preparativo esportivo' para que o adolescente se afastasse dos "centros perversores, das tascas e bancas de jogo, onde se degradam no vício e baixam à criminalidade" (Moniz de Aragão, 1997, p. 453). A tese afirma que a realização de exercícios físicos e os cuidados higiênicos, aliados aos apelos morais, são um importante instrumento na relação educação-saúde. O uso obrigatório da caderneta sanitária é defendido como um modo de acompanhar a situação de saúde dos indivíduos, visando ao "aproveitamento do grupo e de cada um de seus componentes", e, na perspectiva de Foucault (2002), funcionaria como um dispositivo de poder, utilizado para o controle das condições de vida da população, no caso, das crianças.

Moniz de Aragão justifica ainda que, com a caderneta, é possível avaliar facilmente o desenvolvimento da criança, o que favorece

(...) as medidas a serem tomadas quanto à sua educação, sobretudo dos retardados e anormais ou dos que apresentam defeitos físicos necessitando de correção, facilitando a remoção para centros especiais, onde haja aparelhos apropriados à reeducação e correção de defeitos corporais (1997, p. 454; grifo nosso).

Percebe-se, nessa passagem, a visão higienista e eugênica do autor, ao propor que sejam colocados na mesma categoria os supostos 'retardados e anormais' e aqueles que apresentem defeitos físicos, que também deveriam ser internados em instituições especializadas.

A intervenção médica proposta pretendia afastar do convívio social aqueles indivíduos que pudessem causar transtornos à vida coletiva por causa das suas características físicas, mentais ou morais, consideradas desviantes dos padrões de normalidade da época. O controle se manifesta de 
modo mais intenso quando o autor afirma: “Na ocasião da matrícula, com a apresentação da caderneta, poderá o médico, facilmente, impedir o ingresso de crianças contagiantes na coletividade e indicar serviços que deverão procurar para seu tratamento ou sua educação" (Moniz de Aragão, 1997, p. 454; grifo nosso). O médico seria dotado de tal poder a ponto de estar autorizado a decidir sobre como devia viver cada indivíduo.

A caderneta previa uma série de anotações de dados diversificados e abrangentes, o que revela a preocupação dos médicos higienistas do período. Deveriam ser registradas as medidas da 'circunferência craniana',13 além de serem feitos exames clínicos variados, entre os quais 'exame dos pelos e das unhas'. A caderneta trazia também uma série de perguntas sobre antecedentes hereditários - 'pais vivos?', 'carnal?' 'consanguíneos?' - e outras perguntas como: 'Viciado sexualmente?' ‘Álcool?' 'Bebe?'. A maioria das indagações parece se preocupar principalmente com a procedência da criança, e não propriamente com o estado de saúde em que ela se encontra. Essa investigação minuciosa dos médicos tinha como objetivo evitar a degeneração da raça. Para isso, era necessária a análise das predisposições hereditárias das crianças e detectar aquelas crianças que podiam vir a desenvolver algum tipo de doença, ou mesmo que pudessem apresentar um desvio moral, causados por herança genética.

\section{Considerações finais}

As teses da I Conferência Nacional de Educação de 1927 servem como meio para se compreender um pouco as questões que preocupavam o cenário nacional brasileiro, no que se refere tanto à educação escolarizada quanto à educação da população, vista de forma ampliada a outros espaços sociais além da escola.

Nas nove teses analisadas, o discurso médico-higienista fica bem evidenciado no modo prescritivo e doutrinário do convencimento de educar a população brasileira sobre a necessidade de adquirir hábitos de higiene e asseio, e de cuidar da saúde, principalmente por meio da prevenção. A pretensão dos autores das teses vai muito além das prescrições para o trabalho do professor na sala de aula; eles pretendiam 'formar a consciência sanitária nacional', educando também os indivíduos que não frequentavam a escola - nesse período, a maioria da população - sobre como ter uma vida regrada higiênica e moralmente.

Nesse sentido, a preocupação eugênica também está bastante presente, tanto nas prescrições para o controle da sexualidade das crianças quanto nas instruções para os adultos sobre quem seria apto a se reproduzir. Havia ainda a indicação de quais indivíduos seriam considerados anormais, do ponto de vista físico, mental e moral. Essa preocupação era enfatizada pela 
possibilidade deles se tornarem um transtorno social e, assim, deveriam ficar internados em instituições consideradas apropriadas, com base no dito conhecimento científico divulgado pela medicina na época.

Já o uso recorrente de termos como 'retardados', 'anormais' ou 'raça' mostra uma finalidade mais persuasiva dos argumentos do que propriamente uma comprovação científica do que estava sendo defendido. Os argumentos morais foram os mais utilizados para convencer as pessoas sobre a necessidade de adotar novos hábitos para a 'melhoria da raça brasileira' e o 'progresso do país'. Além disso, as teses tratam as diferenças apenas do ponto de vista individual e deixam de abordar as marcantes diferenças sociais entre a população carente e a elite.

Este trabalho buscou evidenciar a forma como os discursos higienistas presentes na I Conferência Nacional de Educação utilizaram a força persuasiva na tentativa de moldar a sociedade brasileira, conforme Carvalho (1998). Ademais, o trabalho impulsiona a continuidade das indagações, por meio de novas pesquisas sobre os desdobramentos das ações higienistas, que intencionavam a formação de um 'cidadão apropriado' para o país, na primeira metade do século XX no Brasil.

\section{Nota do Editor}

Este trabalho faz parte do processo de pesquisa em História da Educação que está sendo realizado desde 2010, sob o financiamento da Fundação de Amparo à Pesquisa do Estado de Minas Gerais (Fapemig), no Programa de Pós-graduação em Processos Socioeducativos e Práticas Escolares da Universidade Federal de São João del-Rei.

\section{Notas}

1 Professor do Programa de Pós-graduação em Processos Socioeducativos e Práticas Escolares da Universidade Federal de São João del-Rei (UFSJ), São João del-Rei, Minas Gerais, Brasil. Doutor em Educação pela Universidade Metodista de Piracicaba (Unimep). <laerthejr@yahoo.com.br>

Correspondência: Praça Dom Helvécio, 74, sala 2.43, Fábricas, CEP 36301-160, São João del-Rei, Minas Gerais, Brasil. 
2 Pesquisadora na área de História da Educação e integrante do grupo de estudos "A história do pensamento de Foucault e as contribuições para a história da educação". Mestre em Educação pelo Programa de Pós-graduação em Processos Socioeducativos e Práticas Escolares da Universidade Federal de São João del-Rei (UFSJ).<eliane.vianey@ig.com.br>

3 Editado pelo Instituto Nacional de Estudos e Pesquisas Educacionais Anísio Teixeira (Inep) em 1997, o livro reúne 112 teses; delas, 14 não foram localizadas, sendo transcritos apenas seus pareceres nesta publicação.

4 Há também em Os anormais (2002) uma instigante reflexão sobre os investimentos econômicos que o poder realiza para melhorar sua eficácia e diminuir seus custos, utilizando-se de aspectos legais, ou seja, aceitos pelas normas e procedimentos de organização da sociedade.

$5 \mathrm{O}$ termo utilizado por Foucault refere-se ao tratamento dos anormais, isto é, todos aqueles que não se enquadram nas normas, abrangendo os anormais tanto físicos quanto morais. No caso do tratamento de exclusão dado aos anormais, ele situa historicamente o que era feito na Europa com os leprosos, impedidos de entrar nas cidades, ou seja, eram simplesmente excluídos do convívio social.

6 Originalmente, uma tese de doutorado em História e Filosofia da Educação, defendida em 1986, na Faculdade de Educação, da Universidade de São Paulo.

7 As teses são: "Por que se impõe a primazia da educação higiênica escolar", de Belisário Penna; "Educação e higiene mental", de Álvaro Guimarães Filho; e "A higiene nos internatos: estudo das condições sanitárias dos internatos de São Paulo", de Eurico Branco Ribeiro. Não é casualidade o fato de os três serem médicos.

8 Por exemplo, na tese número 8, "A atividade da Associação Brasileira de Educação durante o ano de 1927", no relatório da "Seção de Divertimentos Infantis", há a seguinte afirmação: "esta Seção, em colaboração com a de Cooperação da Família, intensificou a campanha cinematográfica, que é para a Associação Brasileira de Educação a seleção de filmes próprios à infância e à juventude, apelando às autoridades respectivas a repressão ao crime de se intitularem matinées infantis à passagem de películas imorais e às exibições teatrais inconvenientes, como podemos demonstrar apresentando nosso arquivo de programas e reclames de diversas casas de diversões desta Capital" (Associação Brasileira de Educação, 1997, p. 95).

9 Diz Kehl: “Na opinião de Freud, elas [as crianças] revelam, desde tenra idade, o instinto procriador" (1997, p. 433). Na realidade, Freud não trata do instinto procriador, mas da manifestação do desejo na criança, e nele está implícito o desejo 'sexual', que não deve ser confundido com uma manifestação da sexualidade genital.

10 A sífilis era uma doença muito presente e temida no período, pois a ciência ainda desconhecia os antibióticos. Embora pesquisada por Albert Fleming desde 1928, somente a partir de 1943 a penicilina (a primeira forma de antibiótico conhecida) começa a ser divulgada mundialmente.

11 Alfred Binet passou a utilizar os 'métodos psicológicos', inventando "uma série de tarefas que permitiram avaliar de maneira mais direta os diferentes aspectos da capacidade mental (...). Em 1904, Binet foi comissionado pelo ministro da Educação Pública [da França] para desenvolver um estudo com um objetivo específico e prático: desenvolver técnicas 
para identificar crianças cujo fracasso escolar sugerisse a necessidade de alguma forma de educação especial"' (Gould, 1999, p. 151-152).

$12 \mathrm{O}$ relato da tese número 8 sobre "A atividade da Associação Brasileira de Educação durante o ano de 1927" evidencia bem a campanha realizada sobre temas defendidos em algumas seções da ABE, por vários associados. Por exemplo, o presidente da Seção de Higiene e Educação Física, Belisário Penna, esteve "constantemente ausente da Capital, em trabalho, aliás, de educação higiênica por todo o país. Este ano [1927] percorreu grandes trechos do Rio Grande do Norte, da Paraíba, de Pernambuco, de Minas, de São Paulo e do Paraná, tendo realizado nas capitais de alguns deles e em várias cidades e vilas, fábricas e fazendas de outros, 28 preleções sobre assuntos de higiene e profilaxia, acompanhadas sempre de projeções luminosas, fixas e animadas, seguidas de distribuição de folhetos ilustrados sobre o assunto da palestra, além de sete nesta capital, em sede de associações de operários" (Associação Brasileira de Educação, 1997, p. 87).

13 Que remete a Cesare Lombroso (1835-1909). Esse médico italiano, influenciado pela craniometria muito em voga nas teorias racistas na Europa do século XIX, era defensor da frenologia, uma teoria pseudocientífica que dizia ser capaz de determinar características da personalidade pela forma da cabeça (Gould, 1999).

\section{Referências}

ASSOCIAÇÃO BRASILEIRA DE EDUCAÇÃO. A atividade da Associação Brasileira de Educação durante o ano de 1927. In: COSTA, Maria José Franco Ferreira da; SHENA, Denilson Roberto; SCHMIDT, Maria Auxiliadora (Org.). I Conferência Nacional de Educação (1927). Brasília, DF: Inep, 1997, p. 78-98.

CARVALHO, Marta Maria Chagas de. Quando a história da educação é a história da disciplina e da higienização das pessoas. In: FREITAS, Marcos Cezar de (Org.). História social da infância no Brasil. 6. ed. São Paulo: Cortez, 2006, p. 291-310.

Molde nacional e forma cívica: higiene, moral e trabalho no projeto da Associação Brasileira de Educação (1924-1931). Bragança Paulista: Edusf, 1998.

COSTA, Maria José Franco Ferreira da; SHENA, Denilson Roberto; SCHMIDT,
Maria Auxiliadora (Org.). I Conferência Nacional de Educação (1927). Brasília, DF: Inep, 1997.

DE ANGELIS, Nicolau Meira. Pela perfeição da raça brasileira. In: COSTA, Maria José Franco Ferreira da; SHENA, Denilson Roberto; SCHMIDT, Maria Auxiliadora (Org.). I Conferência Nacional de Educação (1927). Brasília, DF: Inep, 1997, p. 437-445.

DECHANDT, Lucia V. Formação do caráter do povo brasileiro. In: COSTA, Maria José Franco Ferreira da; SHENA, Denilson Roberto; SCHMIDT, Maria Auxiliadora (Org.). I Conferência Nacional de Educação (1927). Brasília: Inep, 1997. p. 426-428.

FARIA FILHO, Luciano Mendes de. Dos pardieiros aos palácios: cultura escolar e urbana em Belo Horizonte na Primeira República. Passo Fundo: UPF, 2000. 
FOUCAULT, Michel. Os anormais: curso no Collège de France (1974-1975). São Paulo: Martins Fontes, 2002.

A ordem do discurso: aula inaugural no Collège de France, pronunciada em 2 de dezembro de 1970. 18. ed. São Paulo: Loyola, 2009.

GONDRA, José Gonçalves. Artes de civilizar: medicina, higiene e educação escolar na Corte Imperial. Rio de Janeiro: EdUERJ, $2004 a$.

Combater a 'Poética Pallidez': a questão da higienização dos corpos. Perspectiva, Florianópolis, v. 22, n. esp., p. 121161, jul.-dez. 2004b.

Medicina, higiene e educação escolar. In: LOPES, Eliane Marta Teixeira; FARIA FILHO, Luciano Mendes (Org.). 500 anos de educação no Brasil. 2. ed. Belo Horizonte: Autêntica, 2000, p. 519-550.

GOULD, Sthephen Jay. A falsa medida do homem. 2. ed. São Paulo: Martins Fontes, 1999.

GUIMARÃES FILHO, Álvaro. Educação e higiene mental. In: COSTA, Maria José Franco Ferreira da; SHENA, Denilson Roberto; SCHMIDT, Maria Auxiliadora (Org.). I Conferência Nacional de Educação (1927). Brasília, DF: Inep, 1997, p. 464-470.

HORTA, José Silvério Baia. O hino, o sermão e a ordem do dia: regime autoritário e a educação no Brasil. Rio de Janeiro: Editora UFRJ, 1994.

KEHL, Renato. O problema da educação sexual: importância eugênica, falsa compreensão e preconceitos - como, quando e por quem ela deve ser ministrada. In: COSTA, Maria José Franco Ferreira da; SHENA, Denilson Roberto; SCHMIDT, Maria Auxiliadora (Org.). I Conferência Nacional de Educação (1927). Brasília, DF: Inep, 1997, p. 433-435.

LINHALES, Meily Assbú. A escola, o esporte e a 'energização do caráter': projetos culturais em circulação na Associação Brasileira de Educação (1925-1935). Tese (Doutorado em Educação) - Faculdade de Educação, Universidade Federal de Minas Gerais, Belo Horizonte, 2006.

LUSTOSA, Isabel. Histórias de presidentes: a República no Catete. Petrópolis: Vozes, 1989.

MAGALHÃES, Lúcia. Seleção e estalonagem das classes infantis pela psicometria e pela fisiometria. In: COSTA, Maria José Franco Ferreira da; SHENA, Denilson Roberto; SCHMIDT, Maria Auxiliadora (Org.). I Conferência Nacional de Educação (1927). Brasília, DF: Inep, 1997, p. 107-115.

MONIZ DE ARAGÃO, João Maurício. Assistência médica à infância escolar: cadernetas sanitárias. In: COSTA, Maria José Franco Ferreira da; SHENA, Denilson Roberto; SCHMIDT, Maria Auxiliadora (Org.). I Conferência Nacional de Educação (1927). Brasília, DF: Inep, 1997, p. 452-454.

MOURÃO, Paulo Krüger Corrêa. O ensino em Minas Gerais no tempo da República (1989-1930). Belo Horizonte: Centro Regional de Pesquisas Educacionais em Minas Gerais, 1962.

OSÓRIO, Fernando Luís. Sobre a unidade nacional: pela cultura cívica e pela cultura moral. In: COSTA, Maria José Franco Ferreira da; SHENA, Denilson Roberto; SCHMIDT, Maria Auxiliadora (Org.). I Conferência Nacional de Educação (1927). Brasília, DF: Inep, 1997, p. 260-261.

PENNA, Belisário. Por que se impõe a primazia da educação higiênica escolar. In: COSTA, Maria José Franco Ferreira da; SHENA, Denilson Roberto; SCHMIDT, Maria Auxiliadora (Org.). I Conferência Nacional de Educação (1927). Brasília, DF: Inep, 1997, p. 29-33.

RIBEIRO, Darcy. Aos trancos e barrancos: como o Brasil deu no que deu. 2. ed. Rio de Janeiro: Guanabara, 1986. 
RIBEIRO, Eurico Branco. A higiene nos internatos: estudos das condições sanitárias dos internatos de São Paulo. In: COSTA, Maria José Franco Ferreira da; SHENA, Denilson Roberto; SCHMIDT, Maria Auxiliadora (Org.). I Conferência Nacional de Educação (1927). Brasília, DF: Inep, 1997, p. $478-519$.

VAGO, Tarcísio Mauro. Cultura escolar, cultivo de corpos: educação physica e gymnastica como práticas constitutivas dos corpos das crianças no ensino público primário de Belo Horizonte (1906-1920). Bragança Paulista: Edusf, 2002.
VIDAL, Diana Gonçalves. O exercício disciplinado do olhar: livros, leituras e práticas de formação docente no Instituto de Educação do Distrito Federal (1932-1937). Bragança Paulista: Edusf, 2001.

WEREBE, Maria José Garcia. Grandezas e misérias no ensino do Brasil: 30 anos depois. 2. ed. São Paulo: Ática, 1997.

Recebido em 21/07/2011

Aprovado em 13/04/2012 